\title{
Neutering of cats and dogs in Ireland; pet owner self-reported perceptions of enabling and disabling factors in the decision to neuter
}

Martin J Downes, Catherine Devitt, Marie T Downes, Simon J More

Background: Failure among pet owners to neuter their pets results in increased straying and overpopulation problems. Variations in neutering levels can be explained by cultural differences, differences in economic status in rural and urban locations, and owner perceptions about their pet. There are also differences between male and female pet owners. There is no research pertaining to Irish pet owner attitudes towards neutering their pets. This paper identified the perceptions of a sample of Irish cat and dog owners that influenced their decisions on pet neutering. Methods: This study was conducted using social science (qualitative) methods, including an interview-administered survey questionnaire and focus group discussions. Data was coded and managed using Nvivo 8 qualitative data analysis software Results: Focus groups were conducted with 43 pet (cats and dogs) owners. Two major categories relating to the decision to neuter were identified: (1) enabling perceptions in the decision to neuter (subcategories were: controlling unwanted pet behaviour; positive perceptions regarding pet health and welfare outcomes; perceived owner responsibility; pet function; and the influence of veterinary advice), and (2) disabling perceptions in the decision to neuter (subcategories were: perceived financial cost of neutering; perceived adequacy of existing controls; and negative perceptions regarding pet health and welfare outcomes). Discussion: Pet owner sense of responsibility and control are two central issues to the decision to neuter their pets. Understanding how pet owners feel about topics such as pet neutering, can help improve initiatives aimed at emphasising the responsibility of population control of cats and dogs. 
1 Neutering of cats and dogs in Ireland; pet owner self-reported perceptions of enabling and

2 disabling factors in the decision to neuter.

3 Martin J. Downes ${ }^{1 \& 2}$, Catherine Devitt ${ }^{3}$, Marie T. Bowen ${ }^{4}$, Simon J. More ${ }^{2}$

4 Affiliations

5 1. Centre for Applied Health Economics, Griffith Health Institute, Gold Coast, Queensland, 6 Australia.

7 2. Centre for Veterinary Epidemiology and Risk Analysis, School of Veterinary Medicine, 8 University College Dublin, Dublin, Ireland.

9 3. Consultant Social Science Research Professional, Glendalough, Co. Wicklow

10 4. Greencross Vets, Brisbane, Queensland, Australia.

\section{Corresponding author: Martin J. Downes}

12 Postal Address: Centre for Applied Health Economics, Griffith University, Meadowbrook, QLD

13 4131, Australia.

14 Tel: +61733821303

15 Email: m.downes@epinet.net 


\section{Abstract}

17 Background: Failure among pet owners to neuter their pets results in increased straying and overpopulation problems. Variations in neutering levels can be explained by cultural differences,

19 differences in economic status in rural and urban locations, and owner perceptions about their pet.

20 There are also differences between male and female pet owners. There is no research pertaining to

21 Irish pet owner attitudes towards neutering their pets. This paper identified the perceptions of a

22 sample of Irish cat and dog owners that influenced their decisions on pet neutering.

23 Methods: This study was conducted using social science (qualitative) methods, including an 24 interview-administered survey questionnaire and focus group discussions. Data was coded and 25 managed using Nvivo 8 qualitative data analysis software

26 Results: Focus groups were conducted with 43 pet (cats and dogs) owners. Two major categories 27 relating to the decision to neuter were identified: (1) enabling perceptions in the decision to neuter 28 (subcategories were: controlling unwanted pet behaviour; positive perceptions regarding pet health 29 and welfare outcomes; perceived owner responsibility; pet function; and the influence of 30 veterinary advice), and (2) disabling perceptions in the decision to neuter (subcategories were: 31 perceived financial cost of neutering; perceived adequacy of existing controls; and negative 32 perceptions regarding pet health and welfare outcomes).

33 Discussion: Pet owner sense of responsibility and control are two central issues to the decision to 34 neuter their pets. Understanding how pet owners feel about topics such as pet neutering, can help 35 improve initiatives aimed at emphasising the responsibility of population control of cats and dogs. 36 
38 Companion animal overpopulation causes significant costs to humans and governments every year

39 (Olson et al., Apr 1; Olson \& Johnston, 1993). Evidence suggests there is a connection between 40 the neutering status of pets and levels of pet straying, with low levels of neutering related to higher 41 levels of straying in pet behaviour (Hsu, Severinghaus \& Serpell, 2003; Diesel, Brodbelt \& 42 Laurence, 2010). The problem of overpopulation may be attributed to numerous factors that are 43 intertwined including; a failure among pet owners to neuter their pets (Hsu, Severinghaus \& 44 Serpell, 2003; Natoli et al., 2006; Soto et al., 2006; Weng et al., 2006), failure to implement early 45 46 neutering of cats and dogs (Ortega-Pacheco et al., 2007; Farnworth et al., 2013)and poor management of stray populations (Marston \& Bennett, 2009; Stavisky et al., 2012) . Therefore there is a responsibility for pet owners to prevent pet pregnancies and to neuter their pets, with welfare organisations encourage pet owners to be responsible in neutering their pets to help reduce the stray/feral dog and cat populations (Dogs Trust, 2009; Dublin Society for Prevention of Cruelty to Animals, 2010).

There are marked differences in neutering rates across the globe. These differences can be explained by variations in cultural differences and attitudes towards neutering, and differences in economic status in rural and urban locations (Berthoud et al., 2011; Torres de la Riva et al., 2013). Differences in the rate of neutering have been reported between the United States and Europe (Trevejo, Yang \& Lund, 2011; Torres de la Riva et al., 2013). One US study reported the prevalence of castration at $82 \%$ in cats and $64 \%$ in dogs (Trevejo, Yang \& Lund, 2011). In the United Kingdom, one study reported that among 431 dog owners, 54\% of dogs were neutered, and there were regional differences between north and south (Diesel, Brodbelt \& Laurence, 2010). Reported levels are similar in Hungary (Kubinyi, Turcsán \& Miklósi, 2009), but much lower in Sweden (Sallander et al., 2001) and Ireland (Downes, Canty \& More, 2009).

61 Perceptions owners have about their pet are also important. Owners are more likely to neuter their pet if they consider it a companion rather than a working animal (Franti et al., 1980; Faver, 2009). Increased awareness about the benefits and harms of sterilization of female cats and dogs was shown to impact positively on the decision to neuter (Faver, 2009). Perrin (2009) reported 
66

67

68

69

reasons for not neutering have been identified using quantitative processes; including believing neutering to be unnecessary, and wanting to use the pet for breeding (Fielding et al., 2002). Other studies showed that participants agreed that cats and dogs have the right to remain whole and have offspring (McKay et al., 2009). Owners thought that desexing changed the personality of their dog (Blackshaw \& Day, 1994) and were concerned about the effect of neutering on the sexuality/masculinity of their pet (McKay et al., 2009). The cost of neutering also presents a barrier (Blackshaw \& Day, 1994; Faver, 2009).

There are differences in neutering levels between cats and dogs, with cat owners more likely to neuter than dog owners (Franti et al., 1980; Leslie et al., 1994; Poss \& Bader, 2007; Downes, Canty \& More, 2009; Faver, 2009; McKay, Farnworth \& Waran, 2009). Referring to neutering among pet dogs, concerns are expressed about neutering aged dogs and the possible impact on increasing the dog's weight (Blackshaw \& Day, 1994). There are also differences in belief and attitudes between male and female owners (Blackshaw \& Day, 1994). Male owners equate neutering with removing the maleness of the dog, and were of the opinion that neutering can change the personality of the pet (male and female). Some $61 \%$ of male owners and $47 \%$ of female owners would not proceed with neutering their dog if they had the choice again (Blackshaw \& Day, 1994). There are implications for the veterinary profession in the pet care recommendations it offers clients around neutering (Scarlett, Sep 15). Veterinarians can play an important role in addressing problems related to neutering and overpopulation, and counselling pet owners to take appropriate action (Voith, 2009). However, there are challenges to achieving the full potential of this role. For example, Diesel, Brodbelt \& Laurence (2010) reported that there is often variation in the veterinarian advice offered to clients. For example, there was little agreement between veterinary practices on the appropriate stage to neuter bitches, with $16.9 \%$ of practices recommending that a bitch should have a first heat before neutering, in comparison to $20.6 \%$ not recommending neutering at all (Diesel, Brodbelt \& Laurence, 2010).

\section{Pet ownership and neutering in Ireland}

There is no research pertaining to the opinions and perspectives of Irish pet owners towards pet neutering. This reflects the wider lack of research on pet ownership and pet care. Downes et al. (Downes, Canty \& More, 2009) reported that some 35\% of households in Ireland have one or more 
95 pet dogs, and $10.4 \%$ of households have one or more pet cats. Of these, $47.3 \%$ of pet dogs and $9676.1 \%$ of pet cats were neutered. Females (in both cats and dogs) were more likely to be neutered

97 than males (Downes, Canty \& More, 2009). Low levels of pet neutering in Ireland, along with the 98 uncounted number of strays reproducing, means that it is difficult to control overpopulation of cats 99 and dogs in Ireland.

\section{Study objectives}

101 Given the lack of information on pet owner perspectives on neutering in Ireland, the aim of this 102 study is to identify the self-reported perceptions of a sample of Irish cat and dog owners that 103 influenced their decisions on pet neutering.

\section{Material and methods}

105 This study was conducted using social science (qualitative) methods and reported using the 106 EQUATOR network reporting guidelines: Consolidated criteria for reporting qualitative research 107 (COREQ) (Tong, Sainsbury \& Craig, 2007). Qualitative methodology can provide rich and 108 detailed information from which to develop models and theories in an area where very little 109 research has taken place (Barbour, 2005), with emphasis placed on inductive inquiry and a 110 subjective view of the insider (Green and Thorogood, 2004). Previous studies examining issues 111 surrounding neutering in pets have mainly used quantitative methods such as questionnaires 112 utilizing predetermined answers as methods of collecting data. However, this approach has some 113 limitations (for example; these methods limit the results to the ideas of the researcher), as 114 acknowledged by some researchers (Robertson, 2003). Also while statistical methods can provide 115 some insight into the associations between neutering and attitudes, they can rarely account for all 116 observed variation, leaving a gap in the evidence to be explored. Focus groups are a common 117 qualitative method. This approach is frequently used to facilitate the expression of ideas and 118 experiences that would be left unexplored in a questionnaire or interview and clarifies participants' 119 perspectives through debate within the group (Kitzinger, 1995).

\section{Study design}


121 Research ethical approval was granted by the University College Dublin (UCD) Human Research

122 Ethics Committee. Participants were required to sign a written form of consent. For the 123 methodology, qualitative research methods - focus groups - were used. Focus groups allowed 124 participants to openly discuss their feelings on neutering, and to indicate their own decisions 125 around neutering their pets.

\section{Participant recruitment}

127 Pet owners were recruited through six different private veterinary practices (three city practices;

128 two in regional towns; and one in a rural area). The practices selected were a convenience sample

129 to ensure compliance and each of these practices agreed to participation in the study. Participants

130 were recruited by the practices, where fliers and posters were put in place and the staff was asked

131 to highlight the research project, to encourage participants to volunteer. Participants were offered

132 a voucher to the value of $€ 50$ for the practice where they were recruited from. Seven focus groups

133 were conducted with 43 participants in total; three to nine participants in each group.

\section{Data collection and analysis}

135 A survey was administered prior to the commencement of the focus groups, to collect information

136 on pet owner profile (age, location, type of dwelling, and household composition) and pet profile

137 information (type and number of pets in participating households). Table 1 presents the participant

138 socio-demographic profile.

139 An interview topic guide was used to direct all of the focus groups. Questions guided the focus 140 groups to explore reasons for pet ownership and pet choice; views and decisions on pet neutering;

141 feeding and weight control; and pet exercise:

142 - Why do you have a pet?

143 - Why did you choose that type of pet?

144 - What are your views on neutering dogs and cats?

145 - What influenced your decision to have your pet neutered or not?

146 - What are your views on pet diets, both homemade and commercial?

147 - What factors influence the weight of your pet? 
- How do you feel about exercising your pet?

149 All focus groups were audio-recorded and transcribed. The coding and the analysis process were assisted using Nvivo 8 (C) QSR International Pty Ltd 2007) qualitative data analysis software.

151 Focus group data were grouped together using codes and themes in accordance with the technique

152 described by Attride-Stirling (2001). Minor thematic codes were developed inductively as the 153 transcripts were reviewed, allowing the data collected to dictate the categories for analysis. After 154 coding, the first two authors mutually agreed on the categories that were to be used in the analysis.

155 Two major categories related to the decision to neuter were identified: (1) Enabling perceptions in 156 the decision to neuter (five subcategories); and (2) Disabling perceptions in the decision to neuter 157 (three subcategories). The subcategories are as follows:

1. Enabling perceptions in the decision to neuter

a. Controlling unwanted pet behaviour

d. Pet function

e. The influence of veterinary advice

2. Disabling perceptions in the decision to neuter

Results

a. Perceived financial cost of neutering

b. Perceived adequacy of existing controls

c. Negative perceptions regarding pet health and welfare outcomes

170 Forty three participants took part in the study. Of these, 81.4\% (35) neutered at least one of their

171 pets. For one of the focus groups, three participants did not turn up leaving only three participants

172 available for the focus group; however this did not impact on the quality of the data collected from

173 this focus group. Though sample sizes are small; more owners had neutered cats than dogs, relative 174 to the sample size. Eight pet owners neutered some of their pets, and the same number did not 
175 neuter their pets. Table 2 details the profile of neutering among pet owners in the study.

176 Enabling perceptions in the decision to neuter

\section{Controlling unwanted pet behaviour}

178 For pet owners, that neutered their pets, neutering provided a means of controlling pet behaviour 179 and reducing the propensity for unwanted and undesired behaviours for the pet owner. Animal 180 behaviours that were identified as unfavourable included fighting between pets, and straying.

181 Neutering reduces the attraction of other cats and dogs to the pet owners' home, and prevents 182 unwanted pets.

183

184

186

\section{5}

196
'It's a case of health issues and trying to keep the cats out of fights.... I think if they're not neutered, they want to be out more. Especially at night and that's putting them at risk from the traffic'

'My dog is neutered... he's a cocker spaniel and they have a reputation for being hyper. Neutering will calm him down. I don't know what happens when dogs go into heat but I do know that the males go mad so I just thought it would be safer, as we walk him [with]out the lead. I'd be petrified if he ran off. I wouldn't know what to do, so I would agree with neutering'.

'I think with cats, you want them there, and a neutered cat stays around the house, they don't wander'.

'One tabby was neutered when I got it and I decided to neuter the others because they would mark their territory and probably fight more. So they are all neutered.'

\section{Positive perceptions regarding pet health and welfare outcomes}

Much discussion was had on the health consequences of neutering for pets. Pet owners referred to the beliefs of others, and their own:

'People said he'd [pet dog] be sluggish, he'd be lethargic, and he'll put on weight. I never 

saw any change. He was a young happy dog. There are these myths going around that [neutering]will change your dog's character. I've never seen that'.

201 Pet owners, in favour of neutering, regard neutering as an effective way of ensuring good animal

202 health for their pets. In addition to controlling the pet's behaviour and reducing the propensity for

203

204

205

206

unwanted pet behaviours, neutering pets was seen as a way of reducing the risk of the spread of disease, infections, and harm caused by fighting (and mating) between animals. For these reasons, neutering was seen as a way of prolonging the life span of the pet.

'With the cats, it's a case of health issues, to avoid the risk of Feline AIDS. They can pick up so much if they're out and fighting'.

'A male cat, I had him neutered because I didn't want him to catch feline AIDS'

'It will prevent them [cat] having infection or uterine cancer... or mammary cancer'.

Both cat and dog owners refer to neutering as increasing the life span of the pet.

'If you have the dog neutered, the bitch neutered, it can extend her life because they don't have to go through the ordeal of giving birth, pups. That can actually add another year or two to the bitch's life span, so that's why I got my present dog neutered'.

'Neutering prolongs the males' [cat] life. They're not fighting and spreading disease'.

'They are pets, it can increase their lifespan because of cancer and diseases, I wanted them [dogs] to live a couple of years longer, it may be selfish, they may have had some great experiences, but I'll hang onto them as long as possible'.

\section{Perceived owner responsibility}

Owner sense of responsibility was apparent in the statements of pet owners who are in favour of neutering. Owners felt a responsibility to reduce unwanted pregnancies, and prevent overpopulation of unwanted cats and dogs.

'A dogyes, you don't want to be responsible for your pet creating a litter of pups or kittens'. 

'Every time you hear figures, how many pets - dogs and cats - that have to be put down every year, because they can't be kept, the shelters are all overrun with them. It's just the thought of it going on, is just horrible'.

'I don't want the responsibility of having kittens or having to find homes. So it is the responsible thing to do'.

'Neutering is more responsible and there are too many puppies around. I have cats and I let them outside. I would hate to have it on my conscience that they were the cause of some other cat having a litter'.

Pet owner comments reflect an emotional perspective on the problem of overpopulation, and not wanting to deal with the implications of finding homes for unwanted kittens and pups, or the implications at an emotional level for the owner.

\section{Pet function}

Keeping a pet (dogs were specifically mentioned in this study) for breeding purposes was identified as a reason for deciding not to neuter.

'[Dogs] should be neutered unless there is a good reason for breeding from them'.

'I had my cat neutered and I can see no point not to, unless you particularly want to breed from the animal for some reason'.

Only one pet owner indicated that they were breeding from their pet dog, and therefore, decided against neutering. There was no reference made to other functional related reasons for owning a pet, e.g., working animal, companionship, etc. .

\section{The influence of veterinary advice}

Only four pet owners referred specifically to the role of veterinary advice in informing their decision to neuter. There was general consensus among the groups that neutering would be complied with if medically required. Two of these pet owners noted they were not in favour of 
247

neutering, but complied with medical advice. There were mixed opinions on this decision, with reference being made to a loss of perceived control over the decision:

'So the advice was that medically I should do it [neuter the pet dog], so I did it and I didn't really think about the rights and wrongs of it at all really'.

'The vet would make the decision for us; she did say the female was quite small to have pups'.

'My decision ended up having to be taken from me... the real decision was that she then got a false pregnancy and the vet said to me this can be a precursor of cancer type of thing and really I'd be better off doing it'.

The influence of media featured very little in the focus groups, but pet owners made reference to information on the number of injured, unhealthy and euthanized cats and dogs.

\section{Disabling perceptions in the decision to neuter}

\section{Perceived financial cost of neutering}

Financial cost was identified as a barrier to improving the prevalence of neutering of pet cats and dogs. This barrier was identified by five participants; though all five had their pet neutered. Instead, concern was raised that the financial costs of neutering would prevent others from neutering their pets.

'I think the cost in Ireland is extremely high.... I had my two dogs done at the same time eight years ago and it was about $£ 350$ to get them neutered by the vet’.

'For the two [cats]... that was my bill when I went to pick them up. That's an awful lot of money... there are people who genuinely can't afford it...'

\section{Perceived adequacy of existing controls}


270 There was an overwhelming perception among those who did not have their pets neutered that 271 adequate control measures were in place, or that neutering was not necessary because the pet was 272 always indoors, or within sight of the owner. These measures include keeping the pet inside a 273 controlled environment, such as the owners' house.

274

275

In this instance, the cats and a male dog are neutered. However, the decision was made not to 294

'The dog we have at the moment is not neutered. It depends on the dog and the environment which it lives, whether you have a garden, whether other people are home during the day, whether the dog is taken out on the lead only'.

'When we got the dog, she was not neutered simply because she was always under control and there was no one living near us. So all of us made sure she was tied, up in her pen'.

'No, he's [pet dog] not neutered. He's around us all the time. He's under strict control around the house'.

'One pet which is completely indoors - She's a total house dog. Someone's always with her if she's outside, there's no need for her to be neutered'.

'[Neutered dogs] get too fat and lazy and it's not hard to lock up a bitch for a month twice a year. I have dogs and bitches at home and I can cope with it... if you've a bitch in heat, you lock her up. I don't agree [with] neutering'.

Specific reference was made to dogs; dogs were perceived as easier to control than cats.

'I didn't neuter the dog but he was never loose outside. There was never any chance he was going to get himself into trouble, because he was either inside with us or outside with one of us, but I did neuter both of the cats. I did that because I didn't want the male to get himself in to trouble in other peoples gardens'.

'I can understand with cats [the need to neuter] because they're out wandering and stuff, but with a dog and you know where they are all the time.' 

'All my cats are neutered and only one male is neutered... cats get diseases when they're out and around whereas the dogs are more home birds'.

\section{Negative perceptions regarding pet health and welfare outcomes}

298 As with the decision to neuter, concerns pertaining to animal health were also influential in the 299 decision not to neuter. These concerns reflect pet owners' believes regarding the consequences 300 and outcomes of neutering.

301

302

303

304

305

306

307

308

309

310

311

312 Self-reported perceptions were organised into those that were i) enabling (i.e. supported the

313 decision to neuter) and ii) disabling (i.e. were against the decision to neuter). All pet owners in

314 favour of neutering had neutered their pets. A minority of those against neutering also had their 315 pets neutered, in compliance with medical advice. Enabling perceptions that supported the decision 316 to neuter included: a desire to control unwanted behaviours (such as straying and fighting);

317 concerns over animal health; a perceived sense of owner responsibility; pet function; and because

318 of veterinary advice. Disabling perceptions that influenced the decision not to neuter included: the 319 perceived financial cost of neutering; the adequacy of existing controls; and concerns over animal 
320 health. It is hoped that, in addition to encouraging further research for an Irish context, the results

321 in this paper will contribute to a better understanding of pet owner behaviour, and contribute to

322 informing veterinary advice and support for adequate pet care.

\section{Discussion of key findings}

324 The health benefits of neutering for pets included decreased risk of cancer, and increased longevity

325 (Michell, 1998). In this study, there was a clear connection between the desire to control pet

326 behaviours (such as straying and fighting), perceived perceptions regarding pet health and welfare

327 outcomes, and the objective of preventing inconvenient implications for the pet owner (such as

328 dealing with unwanted kittens). Neutering was described as prolonging the life span of the pet.

329 This may suggest that owners' decisions are influenced by information beyond their own

330 experiences, such as from a veterinarian (Faver, 2009); however, explicit reference to veterinary

331 advice was made by only a small number of pet owners. For those in favour, neutering was

332 generally considered a matter of responsibility, with reference being made to the need for cat and

333 dog population control. This suggests a level of awareness among these pet owners not only of the

334 health related benefits of neutering, but also the wider problems associated with overpopulation.

335 The importance of normative beliefs and perceived ability are important in explaining the 336 relationship between responsibility and behaviour among pet owners (Rohlf et al., 2010). Recent

337 welfare organizations marketing strategies emphasise the responsibility of population control on

338 pet owners (Dogs Trust, 2009; Dublin Society for Prevention of Cruelty to Animals, 2010). The

339 results show that responsibility and control are two central issues. Pet owners in favour of neutering

340 commented on their sense of responsibility - reflecting an emotional component and an awareness

341 of the implications for the wider cat and dog population if they did not neuter their pets. These pet

342 owners also talked about not wanting to have to respond to unwanted offspring. This reflects their

343 sense of control and responsibility over their pet's behaviour. Neutering provides a means of

344 controlling this behaviour and emotionally reassuring the pet owner. Those against neutering

345 emphasised the adequacy of existing control measures - suggesting a high level of perceived

346 control over the behaviour of their pet, the pet's environment, and the owner's own ability to keep

347 the pet under observation. This is similar to the findings of Perrin (2009) who reported that owners

348 of 'indoor' pets believed that neutering was not necessary. Owner responsibility was not 
349 mentioned by those not in favour of neutering - though pet-related health concerns were 350 emphasised - with pet owners expressing concerns about the invasiveness of the operation, and 351 the risk of pet obesity. Differences were recorded in opinions towards neutering of cats and dogs. 352 Cats were regarded as wanderers, less easy to control and more prone to picking up infection and 353 disease. Dogs were seen as easier to control, and therefore, control measures (such as keeping the 354 dog in a controlled environment, such as indoors) were regarded by some as adequate.

355 Though financial concerns did not feature strongly in the results, the research literature does show 356 that the cost of neutering can present a barrier to pet owners (Blackshaw \& Day, 1994; Faver,

357 2009). At the time of research, the economic climate in Ireland has resulted in less disposable 358 income for people. Pet owners may regard neutering as less of a priority, and instead, implement 359 measures to keep the pet indoors. Recent media coverage has highlighted a growing problem of 360 dog and cat abandonment, associated with a weak economic climate (for example, an article in

361 The Irish Times 'Overcrowded animal centre in urgent appeal for 'responsible' owners after rise 362 in abandoned pet' (The Irish Times, 2012) and an article in the Irish Examiner 'Abandonment on 363 rise during recession'(Irish Examiner, 2012).

364 As there are varying attitudes to neutering in different settings, it is important to conduct research 365 around this area in different countries. Even the level of neutering varies across different countries, 366 for example; only 3\% of dogs in the Coquimbo region of Chile (Acosta-Jamett et al., 2010) and $3671.1 \%$ of dogs in Sweden (Sallander et al., 2001) were neutered compared to 47.3\% of pet dogs in 368 Ireland (Downes, Canty \& More, 2009). There are even within country variations, depending on 369 the methodology used to collect the data i.e: in the US, $64 \%$ of dogs are neutered according to 370 Trevejo, Yang \& Lund (2011) compared to 83\% as estimated by the American Society for the 371 Prevention of Cruelty to Animals (ASPCA, 2011). As far as the authors are aware, the current 372 study is the first study to use qualitative methods to provide rich data on the attitudes and 373 behaviours of pet owners towards neutering and is the first to identify factors associated with 374 neutering in Ireland. With this in mind the data will benefit current practice and to aid in the 375 development of future research in Ireland.

\section{Implications for veterinary advice on neutering}


377 Understanding how pet owners feel about topics such as neutering gives veterinary services the

378 knowledge and understanding to improve their relationship and communication with pet owners

379 (Perrin, 2009). It has been suggested that veterinary practitioners need to communicate more

380 effectively with pet owners around the time of neutering, to ease the burden of neutering on the

381 pet and the owner and to encourage owners to neuter future pets (Blackshaw \& Day, 1994). Diesel,

382 Brodbelt \& Laurence (2010) however, found variations between veterinarian recommendations to

383 pet owners on neutering. This may suggest a lack of consistency in approach and gaps in

384 information on best practice, within the veterinary profession. Though, in this study, the

385 veterinarian did not feature strongly in perceptions of neutering, there is value in considering the

386 role that veterinarians play in working with pet owners. Often the decision to neuter was made by

387 the veterinarian, and some pet owners spoke of the decision being made for them. Effective

388 communication is central. Coe, Adams \& Bonnett, (2008) emphasises the importance of educating

389 clients, providing choices, and using two-way communication. These are important factors that

390 need to be considered by veterinarians when advising on neutering.

391 Various initiatives have been launched in Ireland. The Irish Society for the Prevention of Cruelty

392 to Animals (ISPCA) issued an information leaflet 'It pays to spay or neuter your pet' (Irish Society

393 for Prevention of Cruelty to Animals) which presents information on neutering, and clarification

394 around neutering myths. Another example - the Dogs Trust launched the "it's nicer to neuter"

395 campaign (Dogs Trust, 2009), in an effort to reduce the number of unwanted dogs that are

396 euthanized annually. However, behavioural change cannot be attributed to information alone;

397 attitudinal changes are also required (Ajzen, 1991). The promotion of owner responsibility within

398 the wider community (outside of the confines of the owners home) is one area that can be targeted

399 by neutering initiatives. In addition, the results clearly suggest that pet health is important for pet

400 owners (those for and against neutering). Given the centrality of health concerns for pet owners,

401 attempts to promote neutering should take into account the role of veterinary support and advice

402 in adequately informing pet owners on the health benefits of neutering (Faver, 2009).

403 Limitations in the study design and recommendations for future research

404 In this sample there was an over representation of female owners. There is evidence in the research

405 that shows differences in belief and attitudes between male and female pet owners, with male 
406 owners expressing concern over a change to the pet's personality as a result of neutering 407 (Blackshaw \& Day, 1994). It may be argued that future research pertaining to an Irish population 408 should seek to differentiate differences in belief and levels of neutering between male and female 409 owners. The sample was not stratified by socio-economic group, though different geographical 410 locations, urban and rural, were chosen to minimise this bias. The recruitment of pet owners took 411 place through private veterinary practices. Therefore, it is probable to suggest that participants 412 were more engaged in their pet's health, and could afford to avail of veterinary health care services.

413 While the sample size is not powered to conduct statistical hypothesis testing, as it is not 414 appropriate in a qualitative setting, rather information was collected until saturation of the data 415 was reached. In qualitative research; sampling is conducted to select the most appropriate 416 participants, in this case pet owners (Daly et al., 2007), therefore it may not be necessary to conduct 417 random sampling techniques. In addition, focus groups provide a platform to develop an 418 understanding of participants' behaviour and attitudes based on their knowledge of the situation 419 being addressed and provide a more pleasing setting for discussion to occur leading to richer and 420 more realistic data (Heary \& Hennessy, 2002; Green \& Thorogood, 2004). Thematic analysis 421 allows an interpretation of the data based on experience, and educational and social interactions 422 leading to a better understanding of the issue being addressed (Green \& Thorogood, 2004). Also, 423 to reduce bias, this study was conducted and the data is presented and interpreted in a way that 424 meets the critical appraisal guidelines as outlined by the Cochrane Collaboration Qualitative 425 Methods Group to ensure the high quality of the study (Harris, 2011).

\section{Acknowledgements}

427 The authors would like to acknowledge the invaluable input from all pet owners who participated 428 in the study and and Barna Veterinary Clinic, Blessington Pet Hospital, Primrose Hill Veterinary 429 Hospital, Raheny Veterinary Hospital, Sandymount Pet Hospital and The Animal Health Centre 430 for participating in the study. The authors would also like to thank Margret Nolan and Net Doyle 431 for transcribing the focus group recordings.

\section{References}


433

434

435

436

437

438

439

440

441

442

443

444

445

446

447

448

449

450

451

452

453

454

455

456

457

458

459

460

461

Acosta-Jamett, G., Cleaveland, S., Cunningham, A. A. \& Bronsvoort, B. M. 2010. Demography of domestic dogs in rural and urban areas of the Coquimbo region of Chile and implications for disease transmission. Preventive Veterinary Medicine 94:272-81.

Ajzen I. 1991. The theory of planned behavior. Organizational behavior and human decision processes 50:179-211.

ASPCA. 2011. Pet Statistics [Online]. American Society for the Prevention of Cruelty to Animals. Available: https://www.aspca.org/about-us/faq/pet-statistics [Accessed 01/06/2015].

Attride-Stirling J. 2001. Thematic networks: an analytic tool for qualitative research. Qualitative research 1:385-405.

Barbour RS. 2005. Making sense of focus groups. Medical Education 39:742-750.

Berthoud D, Nevison C, Waterhouse J, Hawkins D. 2011. The prevalence of neutered pet dogs (canis familiaris) across countries of the western world. Journal of Veterinary Behavior: Clinical Applications and Research 6:77-78.

Blackshaw J, Day C. 1994. Attitudes of dog owners to neutering pets: demographic data and effects of owner attitudes. Australian Veterinary Journal 71:113-116.

Coe JB, Adams CL, Bonnett BN. 2008. A focus group study of veterinarians' and pet owners' perceptions of veterinarian-client communication in companion animal practice. Journal of the American Veterinary Medical Association 233:1072-1080.

Daly, J., Willis, K., Small, R., Green, J., Welch, N., Kealy, M. \& Hughes, E. 2007. A hierarchy of evidence for assessing qualitative health research. Journal of Clinical Epidemiology 60:4349.

Diesel G, Brodbelt D, Laurence C. 2010. Survey of veterinary practice policies and opinions on neutering dogs. Veterinary Record 166:455-458.

Dogs Trust. 2009. It's Nicer to Neuter.

Downes M, Canty MJ, More SJ. 2009. Demography of the pet dog and cat population on the island of Ireland and human factors influencing pet ownership. Preventive Veterinary Medicine 92:140-149.

Dublin Society for Prevention of Cruelty to Animals. 2010. Benefits of Spaying or Neutering Your Pet - The Dublin Society for Prevention of Cruelty to Animals | Dublin SPCA. 
462 Farnworth MJ, Adams NJ, Seksel K, Waran NK, Beausoleil NJ, Stafford KJ. 2013. Veterinary

463

464

465

466

467

468

469

470

471

472

473

474

475

476

477

478

479

480

481

482

483

484

485

486

487

488

489

490

491 attitudes towards pre-pubertal gonadectomy of cats: a comparison of samples from New Zealand, Australia and the United Kingdom. New Zealand Veterinary Journal 61:226-233.

Faver CA. 2009. Sterilization of Companion Animals: Exploring the Attitudes and Behaviors of Latino Students in South Texas. Journal of Applied Animal Welfare Science 12:314 - 330.

Fielding, W.J., Samuels, D., Mather, J. 2002. Attitudes and actions of West Indian dog owners towards neutering their animals: A gender issue? Anthrozoos 15:206-226.

Franti CE, Kraus JF, Borhani NO, Johnson SL, Tucker SD. 1980. Pet ownership in rural Northern California (El Dorado County). Journal of the American Veterinary Medical Association 176:143-9.

Green, J. \& Thorogood, N. 2004. Qualitative Methods for Health Research. SAGE Publications Ltd, London.

Harris J., 2011. Chapter 4: Critical appraisal of qualitative research. In: Noyes J, Booth A, Hannes K, Harden A, Harris J, Lewin S, Lockwood C (editors), Supplementary Guidance for Inclusion of Qualitative Research in Cochrane Systematic Reviews of Interventions. Version 1 (updated August 2011). Cochrane Collaboration Qualitative Methods Group, 2011. Available from URL http://carmg.cochrane.org/supplemental-handbook-guidance.

Heary, C.M., Hennessy, E. 2002. The Use of Focus Group Interviews in Pediatric Health Care Research. Journal of Paediatric Psychology 27:47-57.

Hsu Y, Severinghaus LL, Serpell JA. 2003. Dog keeping in Taiwan: its contribution to the problem of free-roaming dogs. Journal of Applied Animal Welfare Science 6:1-23.

Irish Examiner. 2012. Abandonment on rise during recession | Irish Examiner.

Irish Society for Prevention of Cruelty to Animals. It Pays to Spay or Neuter Your Pet.

Kitzinger J. 1995. Qualitative research. Introducing focus groups. BMJ 11:299-302.

Kubinyi E, Turcsán B, Miklósi Á. 2009. Dog and owner demographic characteristics and dog personality trait associations. Behav Processes 81:392-401.

Leslie BE, Meek AH, Kawash GF, McKeown DB. 1994. An epidemiological investigation of pet ownership in Ontario. Canadian Veterinary Journal 35:218-22.

Marston LC, Bennett PC. 2009. Admissions of Cats to Animal Welfare Shelters in Melbourne, Australia. Journal of Applied Animal Welfare Science 12:189-213. 
492 McKay SA, Farnworth MJ, Waran NK. 2009. Current Attitudes Toward, and Incidence of,

493

494

495

496

497

498

499

500

501

502

503

504

505

506

507

508

509

510

511

512

513

514

515

516

517

518

519

520

521

522

Sterilization of Cats and Dogs by Caregivers (Owners) in Auckland, New Zealand. Journal of Applied Animal Welfare Science 12:331 - 344.

Michell AR. 1998. Neutering and longevity in dogs. Veterinary Record 142:288.

Natoli E, Maragliano L, Cariola G, Faini A, Bonanni R, Cafazzo S, Fantini C. 2006. Management of feral domestic cats in the urban environment of Rome (Italy). Preventive Veterinary Medicine 77:180-5.

Olson PN, Johnston SD. 1993. Animal welfare forum: overpopulation of unwanted dogs and cats. New developments in small animal population control. Journal of the American Veterinary Medical Association 202:904-909.

Olson PN, Moulton C, Nett TM, Salman MD. 1991. Pet overpopulation: a challenge for companion animal veterinarians in the 1990s. Journal of the American Veterinary Medical Association 198:1151-2.

Ortega-Pacheco A, Rodriguez-Buenfil JC, Bolio-Gonzalez ME, Sauri-Arceo CH, Jimenez-Coello M, Forsberg CL. 2007. A survey of dog populations in urban and rural areas of Yucatan, Mexico. Anthrozoos 20:261-274.

Perrin T. 2009. The Business of Urban Animals Survey: The facts and statistics on companion animals in Canada. The Canadian Veterinary Journal 50:48-52.

Poss JE, Bader JO. 2007. Attitudes Toward Companion Animals Among Hispanic Residents of a Texas Border Community. Journal of Applied Animal Welfare Science 10:243 - 253.

Robertson ID. 2003. The association of exercise, diet and other factors with owner-perceived obesity in privately owned dogs from metropolitan Perth, WA. Preventive Veterinary Medicine 58:75-83.

Rohlf VI, Toukhsati S, Coleman GJ, Bennett PC. 2010. Dog Obesity: Can Dog Caregivers' (Owners') Feeding and Exercise Intentions and Behaviors Be Predicted From Attitudes? Journal of Applied Animal Welfare Science 13:213-236.

Sallander M, Hedhammar \AA, Rundgren M, Lindberg JE. 2001. Demographic data of a population of insured Swedish dogs measured in a questionnaire study. Acta Veterinaria Scandinavica 42:71-80.

Scarlett JM. 2008. Interface of epidemiology, pet population issues and policy. Preventive Veterinary Medicine 86:188-97. 
523 Soto FRM, Ferreira F, Pinheiro SR, Nogari F, Risseto MR, Souza O de, Amaku M. 2006. Canine

524

525

526

527

528

529

530

531

532

533

534

535

536

537

538

539

540

541 population dynamics in Ibiuna-SP: retrospective study. Brazilian Journal of Veterinary Research and Animal Science 43:178-185.

Stavisky J, Brennan ML, Downes M, Dean R. 2012. Demographics and economic burden of unowned cats and dogs in the UK: results of a 2010 census. BMC Veterinary Research 8:163.

The Irish Times. 2012. Overcrowded animal centre in urgent appeal for "responsible" owners after rise in abandoned pets. Irish Times.

Tong A, Sainsbury P, Craig J. 2007. Consolidated criteria for reporting qualitative research (COREQ): a 32-item checklist for interviews and focus groups. International Journal for Quality in Health Care 19:349-357.

Torres de la Riva G, Hart BL, Farver TB, Oberbauer AM, Messam LLM, Willits N, Hart LA. 2013. Neutering Dogs: Effects on Joint Disorders and Cancers in Golden Retrievers. PLoS ONE 8:e55937.

Trevejo R, Yang M, Lund EM. 2011. Epidemiology of surgical castration of dogs and cats in the United States. Journal of the American Veterinary Medical Association 238:898-904.

Voith VL. 2009. The Impact of Companion Animal Problems on Society and the Role of Veterinarians. Veterinary Clinics of North America: Small Animal Practice 39:327-345.

Weng H-Y, Kass PH, Hart LA, Chomel BB. 2006. Risk factors for unsuccessful dog ownership: An epidemiologic study in Taiwan. Preventive Veterinary Medicine 77:82-95. 


\section{Table $\mathbf{1}$ (on next page)}

Socio-demographic profile for participating pet owners

Table 1: Socio-demographic profile for participating pet owners $(\mathrm{N}=43)$ 
1 Table 1: Socio-demographic profile for participating pet owners $(N=43)$

\begin{tabular}{|c|c|c|c|}
\hline \multicolumn{2}{|c|}{ Socio-demographic variable } & \multirow{2}{*}{$\begin{array}{l}\text { Frequency (\%) } \\
3(7.0)\end{array}$} & \multirow{2}{*}{$\begin{array}{c}\begin{array}{l}\text { Ireland pet } \\
\text { owners }^{\text {a } \%}\end{array} \\
14.3\end{array}$} \\
\hline Age & $18-24$ & & \\
\hline & $25-34$ & $7(16.3)$ & 24.6 \\
\hline & $35-44$ & $5(11.6)$ & 21.6 \\
\hline & $45-54$ & $8(18.6)$ & 17.1 \\
\hline & $55-64$ & $14(32.6)$ & 14.15 \\
\hline & $65+$ & $6(14.0)$ & 8.25 \\
\hline & Total & $43(100.0)$ & 100 \\
\hline \multirow[t]{3}{*}{ Gender } & Female & $30(69.8)$ & 50.7 \\
\hline & Male & $13(30.2)$ & 49.3 \\
\hline & Total & $43(100.00)$ & 100 \\
\hline \multirow[t]{6}{*}{ House Type } & Apartment & $1(2.3)$ & 1.4 \\
\hline & Detached & $18(41.9)$ & 57.2 \\
\hline & Semi detached & $13(30.2)$ & 28.6 \\
\hline & Terraced house & $9(20.9)$ & 10.0 \\
\hline & Missing & $2(4.6)$ & 2.8 \\
\hline & Total & $43(100.00)$ & 100 \\
\hline \multirow{6}{*}{$\begin{array}{l}\text { Household } \\
\text { Composition }\end{array}$} & Lone parent with children & $3(7.0)$ & 8.1 \\
\hline & Married or Cohabiting couple & $11(25.6)$ & 19.84 \\
\hline & Married or Cohabiting couple with children & $13(30.2)$ & 59.3 \\
\hline & Mixed non-family household & $8(18.6)$ & 4.13 \\
\hline & One person & $8(18.6)$ & 8.6 \\
\hline & Total & $43(100.0)$ & 100 \\
\hline \multirow[t]{5}{*}{ Marital Status } & Cohabitating & $3(7.0)$ & 11.4 \\
\hline & Divorced or Separated & $2(4.7)$ & 8.4 \\
\hline & Married & $18(41.9)$ & 57.3 \\
\hline & Single & $20(46.5)$ & 21.7 \\
\hline & Total & $43(100.0)$ & $98.8^{b}$ \\
\hline \multirow{3}{*}{$\begin{array}{l}\text { Urban/Rural } \\
\text { Location }\end{array}$} & Rural & $15(34.9)$ & 38.1 \\
\hline & Urban & $28(65.1)$ & 61.9 \\
\hline & Total & $43(100.0)$ & 100 \\
\hline
\end{tabular}

2 Bold $=$ most frequent category

3 a data taken from Downes et al. 2009

4 b $1.2 \%$ didn't answer. 


\section{Table 2 (on next page)}

Profile of neutering (for cat, dogs, and both) among pet owners

Table 2: Profile of neutering (for cat, dogs, and both) among pet owners ( $N=43$ ) 
1 Table 2: Profile of neutering (for cat, dogs, and both) among pet owners $(\mathrm{N}=43)$

\begin{tabular}{|lcccc|}
\hline Neuter status & Cat & Dog & Both cat and dog & Total \\
\hline Yes & $\mathbf{n}(\%)$ & $\mathbf{n}(\mathbf{\%})$ & $\mathbf{n}(\mathbf{\%})$ & N (\%) \\
\hline Some & $8(29.6)$ & $9(33.3)$ & $10(37)$ & $27(62.8)$ \\
\hline No & $1(12.5)$ & $2(25)$ & $5(18.5)$ & $8(18.6)$ \\
\hline Total & - & $5(62.5)$ & $3(37.5)$ & $8(18.6)$ \\
\hline
\end{tabular}

2 